\title{
EDITORIAL
}

\section{EDITORIAL EDIÇÃO ESPECIAL - MEIOS DE HOSPEDAGEM}

\begin{abstract}
Se quisermos adotar uma perspectiva foucaultiana, não devemos partir de conceitos, nem devemos nos preocupar em chegar a conceitos estáveis e seguros em nossas pesquisas [...]. Muito mais interessante e produtivo é perguntarmos e examinarmos como as coisas funcionam e acontecem e ensaiarmos alternativas para que elas venham a funcionar e acontecer de outras maneiras (VEIGA-NETO, 2014, p. 19).
\end{abstract}

Nosso editorial da primeira edição especial, com o título Meios de Hospedagem, da revista Navus, não poderia começar diferente a não ser pela epígrafe de inspiração foucaultiana, vinda de Alfredo Veiga-Neto, que acabamos de anunciar.

Longe da intenção de formular conceitos estáveis e incitar a uma produção científica rígida, como muitas pesquisas às vezes o fazem, a pesquisa que resultou na publicação desta edição especial e do livro "Indicadores de gestão para os meios de hospedagem", organizado por Elisabete Werlang, Eli Lopes da Silva e Nadi Helena Presser, entra em harmonia com esse pensamento de Veiga-Neto (2014).

Sob essa perspectiva e, assumindo que um trabalho de pesquisa deve ser atribuído sobretudo no desejo, porque caso contrário os resultados podem ser fúteis, é que a condução do Programa de Iniciação Científica (PIC) Senac aconteceu e, de tal forma, que permitiu o aprendizado mútuo de docentes e discentes, de onde foi possível surgir um conjunto extenso de publicações, das quais esta aqui faz parte.

Assim, é com grande satisfação que lançamos a primeira edição especial da revista Navus, apresentando 11 artigos oriundos dos subprojetos da pesquisa que objetivou propor indicadores de gestão para os meios de hospedagem e Tesauro de Turismo e Meios de Hospedagem.

Relatamos aqui um pouco desta experiência, vivenciada pela coordenação do programa, 32 professorespesquisadores - neologismo criado por Silva e Werlang (2014) - e 115 alunos nas 9 Faculdades Senac em SC. A este grupo, somaram-se 3 universidades federais e outros professores que, aos poucos, vamos apresentando neste editorial.

Pesquisa é um processo e fomos construindo e reconstruindo o programa na instituição.

O Senac/SC ingressou na educação superior em 2002 e, a partir de 2009, começou a fazer pesquisa e propor ações de extensão em suas faculdades de tecnologia. Cada faculdade desenvolvia os seus projetos e ações, que eram submetidos à comissão de avaliação da mantenedora que avaliava e acompanhava a execução dos mesmos nas faculdades. Os relatos destas pesquisas foram publicados na seção intitulada Relatos de Pesquisa da Navus, criada especialmente para o registro e divulgação destas produções científicas do grupo de pesquisa, entre 2012 e 2013.

Após assumirmos a gestão do programa em 2012, observamos nos anos subsequentes a pesquisa e buscamos identificar como obter resultados de produção científica mais densos e, ao mesmo tempo, mais efetivos para a sociedade. Isto porque acreditamos, como Martín-Barbero 
(2004, p. 239) que a experimentação social são "as estratégias de encontro da universidade com a realidade comunicacional do país, da região e do mundo, isto é, a articulação da docência e da pesquisa com projetos de formulação de demandas sociais e de desenho de alternativas".

O PIC Senac ganhou em 2014 uma nova gestão. As mudanças se iniciaram no foco das linhas de pesquisa de tecnologias de gestão e com a proposta de um projeto de pesquisa único em nível estadual, sendo executado simultaneamente nas nove faculdades do Senac no estado de Santa Catarina. Foi um grande desafio que juntos, docentes, alunos e o Setor de Educação Superior superaram, refletindo na perspectiva da solução de problemas regionais em áreas de relevância social e tecnológica para o setor de comércio de bens, serviços e turismo.

Criado com o título PROPOSIÇÃO DE UM SISTEMA DE INDICADORES DE GESTÃO NA ÁREA DE COMÉRCIO DE BENS, SERVIÇOS E TURISMO, o projeto de pesquisa 2014-2018 da instituição teve como objetivo geral propor indicadores de gestão de negócios para o setor de comércio de bens, serviços e turismo.

Os objetivos específicos para tal proposta foram:

- Compreender como as informações produzidas e utilizadas dentro de um segmento econômico desenvolvem-se simultaneamente com os contextos sociais nos quais as organizações operam, investigando de que forma os fatores ambientais moldam e interferem no comportamento informacional dos gestores;

- identificar e avaliar os indicadores usados nas empresas; avaliar os indicadores usados nas empresas;

- elaborar indicadores para o tipo de negócio, aplicando os pressupostos conceituais e metodológicos para formulação de indicadores de modo que atendam às características a priori e desejáveis preconizadas por Trzesniak (2014);

- testar nas empresas os indicadores formulados; analisar a relevância; comparar seus valores; validar e gerar os indicadores finais para o tipo de negócio.

A gestão estadual do programa estabeleceu 21 etapas para o ciclo do projeto de pesquisa, com 3 fases distintas: planejamento, criação e aplicação (Figura 1).

Figura 1 - Etapas da pesquisa PIC SENAC

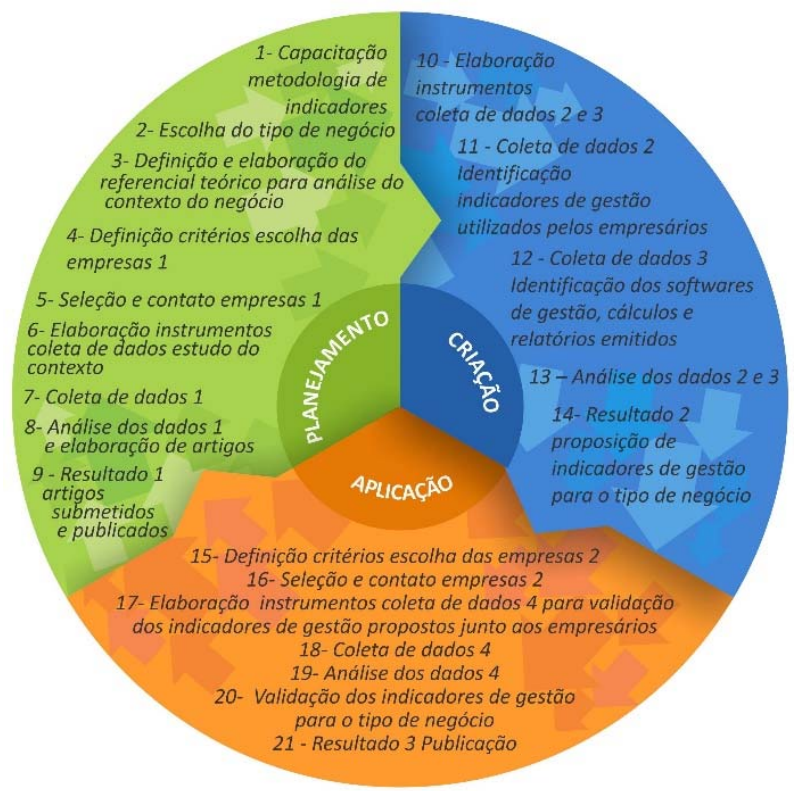

Fonte: os autores (2014). 
O tipo de negócio escolhido para a primeira etapa do projeto foram os MEIOS DE HOSPEDAGEM. Para a viabilização da coleta de dados com os gestores da rede hoteleira, foi firmada uma parceria com a Associação Brasileira da Indústria de Hotéis - ABIH-SC, assinada na abertura do ENCATHO 2014, com a presença do presidente da ABIH-SC, Samuel Koch, do Presidente da Fecomércio, Bruno Breithaupt e do Diretor Regional do Senac/SC, Rudney Raulino.

A perspectiva foi de estabelecer um Programa de Iniciação Científica que formasse não apenas alunos, como tradicionalmente acontece com esse tipo de programa nas universidades, mas que os professores também pudessem ser formados pelo processo da pesquisa em si.

$\mathrm{Na}$ execução do projeto de pesquisa estadual, formamos pesquisadores. Em 2014, foram 29 docentes da instituição inseridos no programa, que tiveram a missão da iniciação científica dos alunos da graduação.

No mesmo ano ocorreu um encontro estadual do grupo, com o objetivo de reflexão sobre a pesquisa científica e a capacitação para a formulação de indicadores de gestão, realizada pelo pesquisador Dr. Piotr Trzesniak.

No segundo semestre de 2014 houve encontros regionais, nas Faculdades de Florianópolis, Blumenau e Chapecó, com o objetivo de alinhamento da condução do projeto estadual, coordenados pela professora Dra. Nadi Helena Presser.

Como estrutura de apoio e de comunicação entre os pesquisadores das diversas cidades do estado de Santa Catarina, participantes da pesquisa, foi criado um espaço no Ambiente Virtual de Aprendizagem (AVA) da instituição, que permitiu a formação de discussão com temáticas que envolveram os docentes e os alunos dos cursos de graduação.

O projeto de pesquisa estadual apenas havia começado e publicações científicas internacionais foram realizadas. Os pesquisadores do PIC Senac, Elisabete Werlang e Eli Lopes da Silva publicaram artigo em Portugal intitulado O PROFESSORPESQUISADOR E A NECESSIDADE DE PARCERIAS: COOPERAÇÃO ENTRE INSTITUIÇÕES DE ENSINO SUPERIOR E INICIATIVA PRIVADA, que refletiu sobre projeto de pesquisa acadêmico viabilizado com parceria entre instituição de ensino superior e iniciativa privada. Propôs o neologismo professorpesquisador, apontou os desafios enfrentados por este profissional e as parcerias como seu amparo. Abordou aspectos sociais e materiais do estudo científico desenvolvido por Latour e sobre a pesquisa na docência a partir das reflexões de Pedro Demo. Formulou considerações a respeito das parcerias estabelecidas e ações que podem facilitar o processo de pesquisa do professorpesquisador. Argumentou em favor da necessidade de criar condições, principalmente viabilizando parcerias, para que as pesquisas empíricas possam ser realizadas.

Para a identificação das empresas estudadas, foi criado um Banco de Dados que apresenta a caracterização dos meios de hospedagem de Santa Catarina. As informações iniciais foram fornecidas pela ABIH-SC, pelo Ministério do Turismo, por intermédio da Secretaria de Estado de Turismo, Cultura e Esporte de SC, e oriundas dos dados contidos no sistema CADASTUR. Em outro momento, foram cruzadas as informações já levantadas pelos pesquisadores e atualizadas pelos alunos bolsistas das faculdades.

O Banco de Dados PIC Senac armazenou informações dos 352 estabelecimentos distribuídos em 58 municípios de SC com 116 dados para contatos dos estabelecimentos. $\mathrm{O}$ acesso ao banco de dados se deu por um endereço eletrônico divulgado internamente na instituição, com senhas criadas para os pesquisadores líderes de pesquisa das faculdades.

Na etapa 3 (Figura 1), de definição e elaboração do referencial teórico e análise do contexto do negócio, foram desenvolvidas pela equipe 16 subprojetos (Quadro 1). 
Quadro 1 - Subprojetos de pesquisa

\begin{tabular}{|c|c|c|c|}
\hline & TÍTULO & PESQUISADORES & FACULDADES \\
\hline 01 & $\begin{array}{l}\text { Estudo da competividade dos meios de } \\
\text { hospedagem }\end{array}$ & Randal Gomes & Jaraguá do Sul \\
\hline 02 & $\begin{array}{l}\text { Modelos de certificação adotados nos } \\
\text { meios de hospedagem }\end{array}$ & $\begin{array}{l}\text { Giane Carla Kopper Muller } \\
\text { Diego Pasqualini }\end{array}$ & Blumenau \\
\hline 03 & $\begin{array}{l}\text { Aspectos jurídicos do turismo e } \\
\text { hospitalidade no Brasil: a existência de } \\
\text { marcos regulatórios para o setor }\end{array}$ & Nilzo Felisberto & Criciúma \\
\hline 04 & $\begin{array}{l}\text { Tecnologias da informação e } \\
\text { comunicação aplicadas ao turismo: } \\
\text { possibilidades e tendências }\end{array}$ & $\begin{array}{l}\text { Carlos Rocha } \\
\text { Eli Lopes da Silva } \\
\text { Flávio Iwao Yamanaka }\end{array}$ & $\begin{array}{l}\text { Criciúma e } \\
\text { Florianópolis }\end{array}$ \\
\hline 05 & Tipologia dos meios de hospedagem & Délcio Dallagnollo & Blumenau \\
\hline 06 & $\begin{array}{l}\text { Competências profissionais e classe de } \\
\text { comportamentos requeridos no } \\
\text { mercado de trabalho nos meios de } \\
\text { hospedagem }\end{array}$ & $\begin{array}{l}\text { Creici Lamonato e Nadi } \\
\text { Helena Presser }\end{array}$ & $\begin{array}{l}\text { Chapecó e } \\
\text { UFPE }\end{array}$ \\
\hline 07 & $\begin{array}{l}\text { Conteúdos informacionais expressos nas } \\
\text { redes sociais - manifestações dos } \\
\text { hóspedes dos meios de hospedagem }\end{array}$ & $\begin{array}{l}\text { Márcio Luis Kroth } \\
\text { Julien } \\
\text { Nadi Helena Presser }\end{array}$ & $\begin{array}{l}\text { Jaraguá do Sul } \\
\text { e UFPE }\end{array}$ \\
\hline 08 & $\begin{array}{l}\text { Sistema de classificação dos meios de } \\
\text { hospedagem - um mecanismo de } \\
\text { gestão da informação }\end{array}$ & $\begin{array}{l}\text { Valdicleia Aparecida } \\
\text { Ferreira }\end{array}$ & Caçador \\
\hline 09 & $\begin{array}{l}\text { A classificação dos meios de } \\
\text { hospedagem na perspectiva do cliente }\end{array}$ & $\begin{array}{l}\text { Scheine Neis Alves da Cruz } \\
\text { De Bastiani }\end{array}$ & Caçador \\
\hline 10 & $\begin{array}{l}\text { Estrutura terminológica dos meios de } \\
\text { hospedagem: vocabulário tecnológico }\end{array}$ & $\begin{array}{l}\text { Marília Koening } \\
\text { Cláudia Nandi }\end{array}$ & Tubarão \\
\hline 11 & $\begin{array}{l}\text { Destino turístico e hospedagem: o papel } \\
\text { das agências de viagens e dos } \\
\text { operadores de turismo }\end{array}$ & $\begin{array}{l}\text { Fabiana Rosana da Silva } \\
\text { Suzana Rodrigues Macedo }\end{array}$ & Florianópolis \\
\hline 12 & $\begin{array}{l}\text { Estudo das ocupações dos meios de } \\
\text { hospedagem com base nas estações }\end{array}$ & Karin Mesacasa Schwab & Chapecó \\
\hline 13 & $\begin{array}{l}\text { As potencialidades turísticas do roteiro } \\
\text { Caminhos da Fronteira }\end{array}$ & $\begin{array}{l}\text { Ademir Zimermann } \\
\text { Emerson Luiz Pereira }\end{array}$ & $\begin{array}{l}\text { São Miguel do } \\
\text { Oeste }\end{array}$ \\
\hline 14 & $\begin{array}{l}\text { Institucionalização da Ciência do } \\
\text { Turismo: análise dos cursos de } \\
\text { graduação e pós-graduação no Brasil } \\
\text { sob a ótica da Ciência da Informação }\end{array}$ & $\begin{array}{l}\text { Nadi Helena Presser e } \\
\text { Elisabete Werlang }\end{array}$ & $\begin{array}{l}\text { UFPE e } \\
\text { Administração } \\
\text { Regional Senac }\end{array}$ \\
\hline 15 & $\begin{array}{l}\text { Formulação de indicadores para o setor } \\
\text { financeiro dos meios de hospedagem }\end{array}$ & $\begin{array}{l}\text { Luís Umberto Allievi } \\
\text { Frizzon }\end{array}$ & Chapecó \\
\hline 16 & $\begin{array}{l}\text { Contexto social dos meios de } \\
\text { hospedagem - um campo de } \\
\text { informações }\end{array}$ & $\begin{array}{l}\text { Nadi Helena Presser, } \\
\text { Elisabete Werlang e Eli } \\
\text { Lopes da Silva }\end{array}$ & $\begin{array}{l}\text { UFPE e } \\
\text { Administração } \\
\text { Regional Senac }\end{array}$ \\
\hline
\end{tabular}

Fonte: Dados da pesquisa (2016) 
Convidados pela coordenação estadual, dois doutores pesquisadores do Departamento de Ciências da Administração do Centro Socioeconômico da UFSC ingressaram no grupo para também investigarem os meios de hospedagem de Santa Catarina (Quadro 2).

Quadro 2 - Subprojetos de pesquisadores de outras instituições

\begin{tabular}{|l|l|l|l|}
\hline & SUBPROJETO & PESQUISADOR & INSTITUIÇÃO \\
\hline 17 & $\begin{array}{l}\text { Indicadores de marketing para meios de } \\
\text { hospedagem }\end{array}$ & Martin Petroll & UFSC e UFPR \\
\hline 18 & $\begin{array}{l}\text { Indicadores de reponsabilidade social } \\
\text { corporativa para meios de hospedagem }\end{array}$ & Evelize Welzel & UFSC \\
\hline
\end{tabular}

Fonte: Dados da pesquisa (2016)

Os 18 subprojetos desenvolvidos exigiram diversas coletas de dados que foram realizadas em 2015 e 2016. Os pré-testes foram realizados pelos professores pesquisadores das faculdades, com a contribuição da profa. Thays Regina de Souza Raiser Cruz, da Faculdade Senac Palhoça, que antes mesmo do início da oferta dos cursos de graduação tecnológica naquela unidade, já estava contribuindo com o projeto de pesquisa.

O Quadro 3 apresenta algumas coletas de dados realizadas pela pesquisa.

Quadro 3 - Coletas de dados

\begin{tabular}{|l|l|l|}
\hline PROJETO & METODOLOGIA DA COLETA & PÚBLICO \\
\hline $\begin{array}{l}\text { A classificação dos meios de } \\
\text { hospedagem na perspectiva do cliente } \\
\text { (subprojeto 09) }\end{array}$ & $\begin{array}{l}\text { Questionário no Google Docs } \\
\text { Enviado pelo SBTur }\end{array}$ & $\begin{array}{l}\text { Clientes do SBTur, que } \\
\text { são hóspedes habituais }\end{array}$ \\
\hline $\begin{array}{l}\text { Destino turístico e hospedagem: o papel } \\
\text { das agências de viagens e dos } \\
\text { operadores de turismo (subprojeto 11) }\end{array}$ & $\begin{array}{l}\text { Questionário no Google Docs } \\
\text { Enviado pela ABIH/SC }\end{array}$ & $\begin{array}{l}\text { Meios de Hospedagem } \\
\text { Associados ABIH/SC }\end{array}$ \\
\hline Tecnologias nos meios de hospedagem & $\begin{array}{l}\text { Questionário no Google Docs } \\
\text { Enviado pelo e-mail PIC } \\
\text { Senac }\end{array}$ & $\begin{array}{l}\text { Meios de Hospedagem } \\
\text { cadastrados no } \\
\text { Cadastur }\end{array}$ \\
\hline $\begin{array}{l}\text { Pesquisa com os meios de hospedagem } \\
\text { de Santa Catarina - Conhecer as práticas } \\
\text { de gestão de pessoas relacionadas aos } \\
\text { processos de recrutamento e seleção e } \\
\text { treinamento e desenvolvimento. }\end{array}$ & $\begin{array}{l}\text { Questionário no Google Docs } \\
\text { pesquisadores }\end{array}$ & $\begin{array}{l}\text { Meios de Hospedagem } \\
\text { cadastrados no } \\
\text { Cadastur }\end{array}$ \\
\hline $\begin{array}{l}\text { Relatórios das ouvidorias / fale conosco } \\
\text { dos meios de hospedagem }\end{array}$ & $\begin{array}{l}\text { Contato direto com } \\
\text { empresários indicados pela } \\
\text { Marcus Hardt Consultoria }\end{array}$ & $\begin{array}{l}\text { Gestores de meios de } \\
\text { hospedagem }\end{array}$ \\
\hline
\end{tabular}

Fonte: Dados da pesquisa (2016)

O Quadro 4 apresenta um resumo da produção científica publicada em revistas científicas e evento. 
Quadro 4 - Produção científica publicada

\begin{tabular}{|l|l|l|l|}
\hline ARTIGO & AUTORES & REVISTA & EDIÇÃO \\
\hline $\begin{array}{l}\text { O professorpesquisador e } \\
\text { a necessidade de } \\
\text { parcerias: cooperação } \\
\text { entre instituições de } \\
\text { ensino superior e } \\
\text { iniciativa privada }\end{array}$ & $\begin{array}{l}\text { Eli Lopes da Silva e } \\
\text { Elisabete Werlang }\end{array}$ & $\begin{array}{l}\text { XII Congresso da Sociedade } \\
\text { Portuguesa de Ciências da } \\
\text { Educação da Universidade } \\
\text { de Trás-Os-montes e Alto } \\
\text { Douro (Vila Real - Portugal) }\end{array}$ & Evento 2014 \\
\hline $\begin{array}{l}\text { Competências } \\
\text { profissionais e classe de } \\
\text { comportamentos } \\
\text { requeridos no mercado } \\
\text { de trabalho nos meios de } \\
\text { hospedagem }\end{array}$ & $\begin{array}{l}\text { Creici Lamonato e } \\
\text { Nadi Helena Presser }\end{array}$ & Revista Turismo em Análise & Volume 26 \\
\hline $\begin{array}{l}\text { As redes sociais no setor } \\
\text { da hospitalidade - } \\
\text { gerenciando as } \\
\text { manifestações dos } \\
\text { hóspedes }\end{array}$ & $\begin{array}{l}\text { Nadi Helena Presser; } \\
\text { Márcio Luís Kroth; } \\
\text { Julien Ariani de Souza } \\
\text { Laudelino; Phelipe } \\
\text { Rafael Alves de } \\
\text { Menezes }\end{array}$ & $\begin{array}{l}\text { Revista Hospitalidade } \\
\text { ISSN 1807-975X }\end{array}$ & Volume 13 \\
\hline $\begin{array}{l}\text { Contexto informacional - } \\
\text { o fenômeno da } \\
\text { hospitalidade }\end{array}$ & $\begin{array}{l}\text { Nadi Helena Presser } \\
\text { Eli Lopes da Silva } \\
\text { Elisabete Werlang }\end{array}$ & Informação \& Sociedade & No prelo \\
\hline
\end{tabular}

Fonte: Dados da pesquisa (2016)

Para alinhamento do grupo de pesquisa estadual e socialização do andamento dos subprojetos, foram realizados também dois encontros técnicos em 2015.

O primeiro foi em Florianópolis de 2 a 4 de março. O evento teve como objetivos a socialização dos subprojetos de pesquisa desenvolvidos pelos pesquisadores, feedbacks da coordenação científica e a capacitação dos professores pesquisadores. $\mathrm{O}$ encontro contou com a presença de 34 participantes, entre pesquisadores e coordenadores de Núcleo da Educação Superior das Faculdades Senac em Santa Catarina. A abertura foi com a palestra do Prof. Dr André Martins que versou sobre CIÊNCIA E CIENTIFICISMO.

No segundo semestre, em função da redução de custos, a proposta foi de uma agenda individual com duração máxima de $1 \mathrm{~h} 30 \mathrm{~min}$ com os pesquisadores por projeto, realizadas no período de 08 a 14 de julho transmitida pela sala de reuniões do $6^{\circ}$ andar do departamento regional. Este encontro teve como objetivo a orientação individual dos pesquisadores, conforme necessidades e andamentos dos 18 subprojetos. Foram atendidas as faculdades: Jaraguá do sul subprojetos 1 e 7; Caçador - subprojeto 09; Blumenau - subprojetos 2 e 5; Tubarão - subprojeto 10; Criciúma - Banco de Dados. Pela proximidade das equipes, foram realizados encontros presenciais com a equipe de Florianópolis, envolvida no subprojeto 11 e com os pesquisadores da UFSC dos subprojetos 17 e 18.

Com verba parcial do CNPq e própria, os pesquisadores coordenadores estaduais de Florianópolis do PIC Senac realizaram visita técnica à UFPE para construção e validação do instrumento da principal coleta de dados de 2015. O instrumento, que consiste em um roteiro para entrevistas com os gestores dos meios de hospedagem, teve o objetivo de identificar quais 
indicadores de gestão são utilizados no dia a dia pelos hoteleiros de Santa Catarina. A equipe se reuniu com a coordenadora científica do projeto, Dra. Nadi Helena Presser e com o Dr. Piotr Trzesniak, criador da metodologia de gestão de indicadores utilizada na pesquisa.

Depois do pré-teste do instrumento, realizado em Florianópolis, com empresário indicado pela $\mathrm{ABIH} / \mathrm{SC}$, foram realizadas 13 entrevistas em 6 cidades catarinenses pelos professores pesquisadores, conforme Quadro 5.

Quadro 5 - Hotéis entrevistados

\begin{tabular}{|c|c|}
\hline Blumenau & 02 \\
\hline Criciúma & 03 \\
\hline Chapecó & 02 \\
\hline Caçador & 02 \\
\hline Florianópolis & 01 \\
\hline Jaraguá & 03 \\
\hline TOTAL & 13 \\
\hline
\end{tabular}

Fonte: Dados da pesquisa (2016).

Identificados na coleta de dados do subprojeto de TI - como os softwares de gestão mais utilizados no estado, os pesquisadores deste grupo intermediados pela $A B I H$, realizaram - na sede da associação - entrevistas com os representantes dos softwares de gestão Silbeck, Desbravador e Bematech que tiveram como objetivo identificar os tipos de relatórios que os sistemas fornecem e de que forma eles auxiliam os gestores nas tomadas de decisão. A interface da ABIH com os representantes dos softwares foi fundamental para que tivéssemos acesso a estas informações.

O livro "Indicadores de gestão para os meios de hospedagem", citado na introdução deste editorial, embora se constitua como a principal publicação conforme objetivo da pesquisa, que foi a proposição de indicadores, é apenas uma parte de toda a produção científica gerada pelo grupo de pesquisa, como se pode ver neste relato.

Os resultados esperados pela sociedade virão pelas futuras ações de extensão e pelas parcerias que já estão sendo firmadas com os stakeholders do contexto organizacional da pesquisa.

Concordando com pensamento de Latour $(2012$, p. 69) que, "por razões científicas, políticas e mesmo morais, não convém que os pesquisadores definam antes dos atores, e no lugar deles, o elemento básico de que o mundo social é feito", acreditamos que todas as parcerias estabelecidas durante a pesquisa, os resultados encontrados e os projetos futuros, apontam para uma solução estratégica de gestão que vincula, de forma indissociável, os meios de hospedagem com a academia.

Eli Lopes da Silva

Elisabete Werlang

Nadi Helena Presser

Editores 


\section{REFERÊNCIAS}

LATOUR, Bruno. Reagregando o social: uma introdução à teoria do Ator-Rede. Salvador: EDUFBA, 2012.

MARTÍN-BARBERO, Jesús. Ofício de cartógrafo. São Paulo: Loyola, 2004.

SILVA, Eli Lopes da; WERLANG, Elisabete. O Professorpesquisador e a necessidade de parcerias: cooperação entre Instituições de Ensino Superior e a Iniciativa Privada. In: Congresso da Sociedade Portuguesa de Ciências da Educação (SPCE), 12., 2014, Vila Real. Anais do XII SPCE. Vila Real: SPEC, 2014.

TRZESNIAK, Piotr. Indicadores quantitativos: como obter, avaliar, criticar e aperfeiçoar. Navus Revista de Gestão e Tecnologia, Florianópolis, SC, v. 4, n. 2, p. 05-18, jul./dez. 2014.

VEIGA-NETO, Alfredo. Foucault \& a Educação. 3. ed. Belo Horizonte: Autêntica Editora, 2014. 